\title{
Distance anatomy education during the COVID-19 pandemic: correspondence
}

\author{
Rujittika Mungmunpuntipantip ${ }^{1} \cdot$ Viroj Wiwanitkit $^{2}$
}

Received: 10 January 2022 / Accepted: 24 January 2022 / Published online: 30 January 2022

(c) The Author(s), under exclusive licence to Springer-Verlag France SAS, part of Springer Nature 2022

\section{Dear Editor,}

We would like to share ideas on the publication "Evaluation of views and perceptions of the medical faculty students about distance anatomy education during the COVID-19 pandemic [2]". Özen et al. concluded that "The COVID-19 pandemic has provided an unexpected experimental environment. The demand for .... in solving the problems of distance anatomy education and in the formation of future anatomy education styles [2]". We agree that the distance anatomy education is useful during pandemic and there are many challenging issues on the new approach. Teaching sessions in various settings must be replaced with online education. The anatomy knowledge provided by the internet is beneficial. Although it can deliver content, pupils may lose precise proficiency when practicing with a real human body.

The dilemma on the opposite side of the coin is another topic that receives little attention. A student's concentration may be harmed as a result of a social media session. In rare cases, social media use might result in health problems. If there is insufficient quality control of light and sound, it is possible to have eye and ear problems, sleep problems, and even induce seizures [1]. Finally, it should note that the report by Özen et al. basically takes a photograph of the ideas of the students regarding online anatomy education just in COVID-19 [2]. The potential effect of online anatomy education on the health of the students that is hereby mentioned is an additional issue that is little mentioned in the literature. Long-term consequences of online education must be considered by educators as well as institutions. So, this commentary is considered as a reminder.

Author contributions RM: substantial contributions to study conception and design, substantial contributions to acquisition of data, substantial contributions to analysis and interpretation of data, drafting the article or revising it critically for important intellectual content, final approval of the version of the article to be published. VW: substantial contributions to study conception and design, substantial contributions to acquisition of data, substantial contributions to analysis and interpretation of data, drafting the article or revising it critically for important intellectual content, final approval of the version of the article to be published.

\section{Declarations}

Conflict of interest None.

\section{References}

1. Hoehe MR, Thibaut F (2020) Going digital: how technology use may influence human brains and behavior. Dialogues Clin Neurosci 22:93-97. https://doi.org/10.31887/DCNS.2020.22.2/mhoehe

2. Özen KE, Erdoğan K, Malas MA (2022) Evaluation of views and perceptions of the medical faculty students about distance anatomy education during the COVID-19 pandemic. Surg Radiol Anat 44:61-71. https://doi.org/10.1007/s00276-021-02867-7

Publisher's Note Springer Nature remains neutral with regard to jurisdictional claims in published maps and institutional affiliations.
Rujittika Mungmunpuntipantip

rujittika@gmail.com

Private Academic Contulant, Bangkok, Thailand

2 Dr DY Patil University, Pune, India 